\title{
Electro-optic properties of singly and doubly doped lithium niobate crystal by rare earth elements for optoelectronic and laser applications
}

\author{
Nune Mkhitaryan ${ }^{1,2,3,4}$, Jean Zaraket ${ }^{3,4}$, Ninel Kokanyan ${ }^{3,4}$, Edvard Kokanyan ${ }^{1,2}$, and Michel Aillerie ${ }^{3,4, *}$ \\ ${ }^{1}$ Institute for Physical Researches, National Academy of Sciences of Armenia, Ashtarak-2, Armenia \\ 2 Armenian State Pedagogical University, Yerevan, Tigran Mets Ave. 17, Yerevan, Armenia \\ ${ }^{3}$ Laboratoire Matériaux Optiques, Photonique et Systèmes, LMOPS, EA 4423, Université de Lorraine, 57070 Metz, France \\ ${ }^{4}$ Laboratoire Matériaux Optiques, Photonique et Systèmes, LMOPS, CentraleSupelec, Université Paris-Saclay, 57070 Metz, \\ France
}

Received: 29 October 2018 / Received in final form: 27 February 2019 / Accepted: 6 March 2019

\begin{abstract}
Congruent lithium niobate (LN) doped with rare-earth elements is a promising host for integrated optic combining the properties straightforwardly associated to the dopant with the good electro-optic (EO) properties. By direct technique based on interferometric optical arrangement at a wavelength of $633 \mathrm{~nm}$ and at room temperature, we have experimentally determined the figure of merit $F=n^{3} r_{\text {eff }}$, $n$ is the refractive index and $r_{\text {eff }}$, the effective EO coefficient) and finally calculated the EO coefficients $r_{\text {eff }}$ of the third-column of the unclamped EO tensor of three series of singly doped $\mathrm{LN}$ with $\mathrm{Yb}^{3+}, \mathrm{Ho}^{3+}, \mathrm{Tm}^{3+}$ and two series of doubly doped $\mathrm{Er}^{3+}-\mathrm{Yb}^{3+}$. It is found that in all the studied opto-geometric configurations, the unclamped figure of merit and consequently the corresponding EO coefficients are relatively constant in the considered dopant concentration range. As the figure of merit, $F$ qualifies crystals for EO modulation and laser applications, all reported results confirm that the LN singly or doubly doped with rare-earth elements are very promising versatile candidates for several multifunctional nonlinear devices in optoelectronic and laser applications.
\end{abstract}

\section{Introduction}

Congruent lithium niobate (LN) is a versatile dielectric material already integrated in optoelectronic devices and laser applications and is promising for new emergent developments in optical sensors and fast optical communications. But all devices based on LN suffer from serious photorefractive damage when LN is grown pure in its usual congruent composition $[1,2]$. Indeed, the relatively low optical damage threshold is a major drawback in applications based on the integration of LN such Pockels cell $[3,4]$. By cons, it is to note that this low optical damage threshold, related to its high photorefractive sensitivity, when it is controlled could be especially interesting for holographic applications [5,6]. Currently, it is well established that the optical damage threshold depends on the amount of intrinsic defects present in the lattice. Thus, for specific optoelectronic and laser applications, the damage threshold could be considerably increased in congruent LN doped with dedicated ions [7] as transition ions or metallic elements, or rare earth elements, which offer the possibility to adapt the advantageous optoelectronic properties of pure samples to integrated optic applications in various passive [8-15] and active [16-19]

\footnotetext{
* e-mail: aillerie@metz.supelec.fr
}

devices [20-23]. Certainly it should be noted a large family of excellent quality Er-doped low-loss waveguide lasers of excellent quality which has been developed emitting in the wavelength range around $1550 \mathrm{~nm}$. Among these one can mention distributed Bragg reflector (DBR), distributed feedback (DFB) and coupled DBR-DFB-lasers were developed in $\mathrm{LiNbO}_{3}$ with a Ti-indiffused waveguides [24-26], free running lasers of the Fabry-Pérot type, selffrequency doubling devices, acousto-optically tunable lasers, harmonically mode-locked lasers and Q-switched lasers $[16,27]$. Some of these devices, as the two last above mentioned, are electro-optically active and utilize the excellent EO properties of LN crystals. Beside the Erdoped LN recently another rare earth ions, Tm-doped channel waveguides have been developed for single photon storage and retrieval [28]. It should be noted that beside the mentioned rare earth ions there are a large number of active ions with numerous electronic transitions. These possible transitions and the interesting EO properties of doped LN, associated to the possible control of the photorefractive damage in co-doped crystals, and these active rare earth ions in LN are potentially very attractive for the development of amplifiers, lasers and quantum memories in LN waveguides. A large number of dopants with a large concentration range can dope congruent $\mathrm{LN}$ and it is possible to combine the properties straightforwardly associated to the dopant with the good electro-optic 
(EO), acousto-optic and non-linear optic properties of LN [29-34]. Among existing possible dopants for LN crystals, some researches point out that divalent ions such as $\mathrm{Mg}^{2+}$ $[1,3,4,35,36]$ and $\mathrm{Zn}^{2+}[4,37,38]$, trivalent ions such as $\mathrm{Sc}^{3+}$ $[39,40]$ and, more recently, $\operatorname{In}^{3+}[41]$, and finally tetravalent ions as $\mathrm{Hf}^{4+}[31,32,42-45]$ and $\mathrm{Zr}^{4+}[46-51]$ can improve the optical damage resistance of LN crystals for specific concentrations. Compared with the $\mathrm{Mg}$ doped congruent LN crystal with $6 \mathrm{~mol} \%$ corresponding to the damage threshold concentration, crystals doped with $\mathrm{Hf}^{4+}$ and $\mathrm{Zr}^{4+}$ present a threshold at around $2 \mathrm{~mol} \%$ for which a comparable photorefractive resistance is achieved $[43,46,50,52,53]$. Thus, with additionally the advantage of a distribution coefficient near one at the threshold concentration, high crystallographic and optical quality $\mathrm{Hf}^{4+}$ and $\mathrm{Zr}^{4+}$ doped crystals with a good optical damage resistance can be grown $[32,46-50]$.

On contrary of the numerous functional properties for divalent and tetravalent-doped LN crystals available in literature as mentioned above, only few studies mentioned the doping of $\mathrm{LN}$ with trivalent ions such as $\mathrm{Sc}^{3+}$ and $\mathrm{In}^{3+}$ $[39,41,45,54,55]$. Except the contributions of $\mathrm{Du}$ et al. $[56,57]$ on LN crystals doped with $\mathrm{Er}^{3+}$ ions, no work has been devoted to the study of the dielectric and electrooptical properties of crystals doped or co-doped with others rare-earth elements as $\mathrm{Er}^{3+}, \mathrm{Yb}^{3+}$ and $\mathrm{Ho}^{3+}$ as function of the concentration and of the structural properties. In a previous work [41], by EO and dielectric measurements it was shown that $\mathrm{In}^{3+}$ doped congruent LN crystals present a smaller optical damage, for a concentration threshold equal to $1.7 \mathrm{~mol} \%$, i.e. about 3 times lower than that of $\mathrm{Mg}^{2+}$ doping $[36,58,59]$. It is to be also of note that the value of the EO coefficient $r_{22}$ (involved when the beam propagation is along the axis $\mathrm{z}$ of the crystal with an electric field applied along $\mathrm{x}$ (or $\mathrm{y})$ ) presents a non-monotonous dependence with the dopant concentration as already observed for crystals doped with other ions such as Zr, Zn or $\mathrm{Mg}[11,38,45,49,50]$. Recently for the first time it was shown that doping of LN crystals with trivalent rare earth ion $\mathrm{Ho}^{3+}$ also leads to an increase of resistance to optical damage for specific dopant concentrations [60]. In addition, it has also been shown that in this crystal, it would be possible to achieve optical cooling and that in fact, this crystal was a material in strong perspective from the point of view of laser applications [61].

Coming back to the structural properties of doped LN crystals and due to the necessary electronic compensation in the lattice structure when doping, the material homogeneity and the optical quality of the crystals are improved with low dopant concentration especially when co-doping with rare-earth ions is considered [62,63]. It is thus challenging to know the EO properties of singly or doubly doped LN with rare-earth elements as $\mathrm{Er}^{3+}, \mathrm{Yb}^{3+}$ and $\mathrm{Ho}^{3+}$ and to determine if the co-doping affects the EO properties of singly doped LN. As above mentioned, Du et al. [56,57] characterized the EO properties of singly $\mathrm{Er}^{3+}$ doped and $\mathrm{In}^{3+}-\mathrm{Er}^{3+}$ co-doped LN crystals. Their experimental results show that $\mathrm{Er}^{3+}$ doping affects the EO coefficient $r_{13}$ (beam propagation along the axis $\mathrm{x}$ (or $\mathrm{y}$ ) of the crystal with an electric field applied along $\mathrm{z}$ ) when the dopant concentration is close the concentration threshold, whereas, $\mathrm{In}^{3+}-\mathrm{Er}^{3+}$ co-doping does not cause the change of the EO coefficients $r_{13}$ and $r_{33}$, which represents an interesting advantage for applications based on EO modulation.

Particularly, when we consider applications integrating pulse lasers based on EO Q-switch, one of the most important features is the voltage required to switch losses. This voltage is defined as the half-wave voltage, $V_{\pi}$ that changes the phase of the light wave that passes through the crystal EO by a value of $\pi$ relative to its initial phase. This voltage depends on the opto-geometric configuration as shown by the relationship

$$
V_{\pi}=\frac{\lambda d}{n^{3} r_{\mathrm{eff}}^{L}}
$$

where $\lambda$ is the vacuum wavelength, $n$ the refractive index seen by the eigen-wave propagating in the crystal, $r_{\text {eff }}$ the absolute value of the effective EO coefficient and $d$ and $L$ are the dimensions of the crystal along the electric-field direction and along the beam-propagation direction. So that, for the qualification of an EO material, we will consider the reduced half-wave voltage $V_{\pi}^{*}$ for which $L=d$. Thus, for the EO Q-switch laser applications, the factor of merit $F=n^{3} r_{\text {eff }}$ is introduced which makes it possible to overcome the wavelength. This equation also has a certain advantage in the comparison of materials for which we do not have the value of the refractive indices because the term $n^{3} r_{\text {eff }}$ appears directly in the expression of the EO modulation allowing for EO characterizations of samples (see Eq. 2).

In the present work, as function of various rare earth elements, we report experimental results and analysis obtained in the characterization of the figure of merit $F$ in the specific opto-geometric configurations involving the unclamped EO coefficients $r_{13}, r_{33}$ and $r_{c}$ of various series of singly and doubly doped LN crystals by rare-earth elements. These coefficients are mainly involved as EO modulator in laser applications. Three series of singly doped $\mathrm{LN}$ with $\mathrm{Yb}^{3+}, \mathrm{Ho}^{3+}, \mathrm{Tm}^{3+}$ and two series of doubly doped $\mathrm{Er}^{3+}-\mathrm{Yb}^{3+}$ elements were characterized by EO measurements performed on a Mach-Zehnder interferometer. Additionally, we have also characterized a pure congruent LN sample allowing us to enlighten the specific role of the dopant in the EO properties.

It is to be of note that numerous studies concerned the $\mathrm{Er}^{3+}-\mathrm{Yb}^{3+}$ co-doped LN but they focus mainly to the luminescence and spectroscopic properties of such compound $[28,64,65]$. Particularly, time-resolved photoluminescence measurements give evidence of an efficient energy transfer from $\mathrm{Yb}^{3+}$ ions to $\mathrm{Er}^{3+}$ ones [66]. To our knowledge, for the first time, the EO properties of $\mathrm{Er}^{3+}$ $\mathrm{Yb}^{3+}$ co-doped LN will be determined by the current work and starting from this initial result, it seems interesting to check the influence of co-doping in the EO properties.

\section{Experimental}

Congruent LN crystals doped with $\mathrm{Yb}^{3+}, \mathrm{Ho}^{3+}, \mathrm{Tm}^{3+}$ and co-doped by $\mathrm{Er}^{3+}-\mathrm{Yb}^{3+}$ impurity ions were grown by the 
Table 1. Characteristics of the studied LN crystals. EO figures of merit, $F=n^{3} r_{\text {eff }}$ and EO coefficients $r_{\text {eff }}$ of the third column of the EO tensor. In calculation of the EO coefficients, we assumed the typical values of the refractive indices for pure congruent crystal (at $T=25^{\circ} \mathrm{C}$ and $\lambda=632.8 \mathrm{~nm}$ ).

\begin{tabular}{llllllllll}
\hline & $\mathrm{N}^{\mathrm{o}}$ & $\begin{array}{l}\text { Dopant } /(\mathrm{mol} \%) \\
\text { In the melt }\end{array}$ & $\begin{array}{l}\text { Dopant/(mol\%) } \\
\text { In the crystal }\end{array}$ & $\begin{array}{l}n^{3} r_{13} \\
(\mathrm{pm} / \mathrm{V})\end{array}$ & $\begin{array}{l}n^{3} r_{33} \\
(\mathrm{pm} / \mathrm{V})\end{array}$ & $\begin{array}{l}n^{3} r_{c} \\
(\mathrm{pm} / \mathrm{V})\end{array}$ & $\begin{array}{l}r_{13} \\
(\mathrm{pm} / \mathrm{V})\end{array}$ & $\begin{array}{l}r_{33} \\
(\mathrm{pm} / \mathrm{V})\end{array}$ & $\begin{array}{l}r_{c} \\
(\mathrm{pm} / \mathrm{V})\end{array}$ \\
\hline Pure cg & 0 & 0 & & 102 & 314 & 213 & 8.5 & 29.4 & 19.9 \\
$\mathrm{Ho}^{3+}$ & $1-1$ & 0.092 & 0.092 & 112 & 315 & 203 & 9.3 & 29.5 & 19.0 \\
& $1-2$ & 0.69 & 0.69 & 99 & 290 & 190 & 8.3 & 27.1 & 17.8 \\
$\mathrm{Tm}^{3+}$ & $2-1$ & 0.009 & 0.012 & 107 & 309 & 201 & 9.0 & 28.9 & 18.9 \\
& $2-2$ & 0.09 & 0.12 & 110 & 314 & 205 & 9.2 & 29.4 & 19.2 \\
$\mathrm{Yb}^{3+}$ & $3-1$ & 0.01 & - & 111 & 332 & 222 & 9.2 & 31.1 & 20.8 \\
& $3-2$ & 0.02 & - & 101 & 297 & 196 & 8.5 & 27.8 & 18.3 \\
& $3-3$ & 1 & 1.2 & 91 & 258 & 167 & 7.6 & 24.2 & 15.6 \\
$\mathrm{Er}^{3+}-\mathrm{Yb}^{3+}$ & $4-1$ & $0.2-0.5$ & $0.33-0.96$ & 103 & 309 & 206 & 8.6 & 28.9 & 19.3 \\
$\mathrm{Er}^{3+}-\mathrm{Yb}^{3+}$ & $4-2$ & $0.5-0.5$ & $0.78-0.93$ & 98 & 262 & 164 & 8.2 & 24.5 & 15.4 \\
& $5-1$ & $0.2-1.0$ & $0.33-1.57$ & 92 & 265 & 173 & 7.7 & 24.8 & 16.2 \\
& $5-2$ & $0.5-1.0$ & $0.62-1.47$ & 100 & 284 & 184 & 8.3 & 26.5 & 17.2 \\
\hline
\end{tabular}

modified Czochralski method in air using a setup with an rf heating furnace and a platinum crucible having a size of $50 \times 3 \times 50 \mathrm{~mm}^{3}$. The $\mathrm{Er}^{3+}, \mathrm{Yb}^{3+}, \mathrm{Ho}^{3+}$ and $\mathrm{Tm}^{3+}$ impurity ions concentrations in the melt were varied between 0 and $1.0 \mathrm{~mol} \%$. The doping with rare earth ions was performed by adding the dopant in their oxide forms into the LN melts' pellets. Special measurements of the concentration of used impurity ions were not performed, but we used corresponding data from the literature. For the case of Er-Yb co-doped samples values of the impurity ions in the crystal were taken from the papers $[67,68]$, for the case of Yb-doped ones from [69], for the case of Tm-doped ones from $[68,70]$. For estimation of Ho concentration in the samples the data from the [68] has been used. The mentioned concentration values of the impurity ions in the crystals under study are presented in the Table 1 . The crystals were pulled along the c-axis at a rate of $1 \mathrm{~mm} / \mathrm{h}$ and a rotation speed of about $20 \mathrm{rpm}$. High purity materials in powder form from Johnson-Mattey $\left(\mathrm{Nb}_{2} \mathrm{O}_{5}\right)$ and Merck $\left(\mathrm{Li}_{2} \mathrm{CO}_{3}\right)$ were used to obtain the initial congruent composition LN powder. During the growth process, a direct electric field (electrical current of about $12 \mathrm{~A} / \mathrm{m}^{2}$ ) was applied to the crystal-melt system in order to obtain single domain crystals directly during the growth process and a rather homogeneous distribution of impurity ions within all the grown crystal.

We have investigated, at room temperature and using a $\mathrm{He}-\mathrm{Ne}$ laser $(633 \mathrm{~nm})$, the unclamped EO coefficients $r_{13}$ and $r_{13}$ using a Mach-Zehnder type interferometric technique with light propagation along the $\mathrm{x}$-axis, polarization parallel to the $\mathrm{y}$ and $\mathrm{z}$ axes, respectively, for the two coefficients, and an applied electric field parallel to the $\mathrm{z}$-axis of the crystals. The associated method is the "Modulation Depth Method" (MDM) previously described in references [71,72]. As a reminder, MDM is a dynamic method in which the EO coefficient is calculated from the measurement of the modulated beam amplitude induced by an ac-voltage applied on the sample under test. In the current study, the peak-to-peak amplitude of the applied ac-voltage is equal to $250 \mathrm{~V}$ at $1 \mathrm{kHz}$, and a lock-in amplifier and an oscilloscope are used for the measurement of the intensity amplitude of the modulated component of the transmitted laser beam.

Under the above-mentioned conditions, within the MDM method, the maximum frequency limit is defined by the specifications of the power supply and the signal acquisition electronic apparatus used for these experiments. In this method, the peak-to-peak amplitude of the sinusoidal modulated beam $\Delta i$ is measured at the point located at $50 \%$ transmission, i.e. to the so-called linear working point corresponding to the $\left(I_{\max }-I_{\min }\right) / 2$ point, with $I_{\max }$ and $I_{\min }$ the maximum and minimum of the transmitted intensity. The absolute value of the effective EO figure of merit can be determined from the experimental intensities and voltage measurements within an equation having the form $[72,73]$

$$
n^{3} r_{\mathrm{eff}}(v)=2 \frac{\lambda d}{\pi\left(I_{\max }-I_{\min }\right) L} \frac{\Delta i(v)}{\Delta V(v)} .
$$

In this equation $\Delta V$ is the corresponding amplitude of the modulated voltage applied to the crystal. From the two effective EO figures of merit corresponding to $r_{13}$ and $r_{33}$, experimentally determined, the combined figure of merit corresponding to $r_{c}$ is calculated by

$$
n_{c}^{3} r_{c}=n_{e}^{3} r_{33}-n_{o}^{3} r_{13} .
$$

The calculation of the unclamped EO coefficients $r_{13}$ and $r_{33}$ were performed for each crystal under investigation. We assumed in calculations, $n_{o}=2.863$ and $n_{e}=$ 2.2025 , which are the typical values of the refractive indices for pure congruent crystal at room temperature and at $\lambda=632.8 \mathrm{~nm}$. The small change in the value of the 

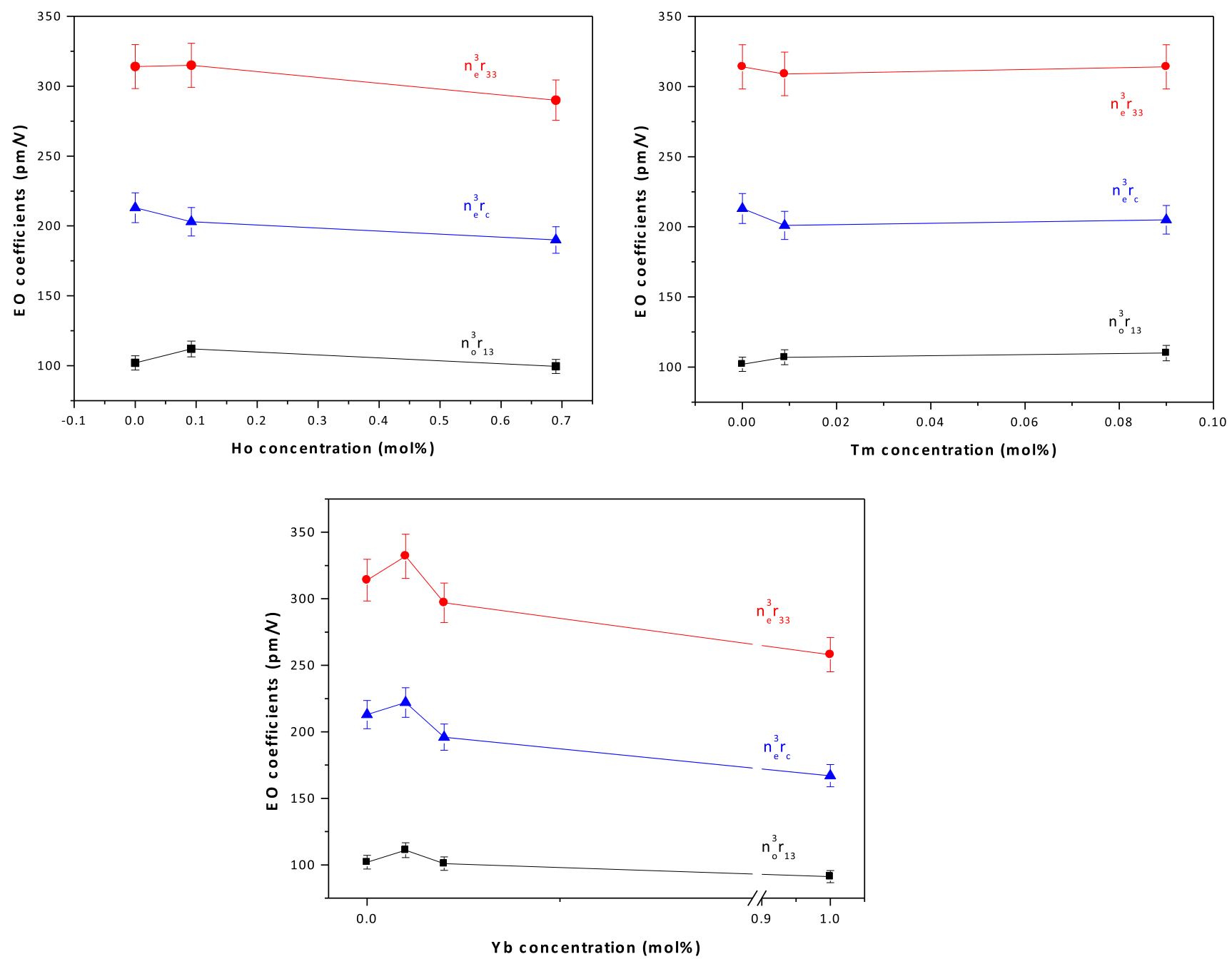

Fig. 1. The experimental $n_{o}^{3} r_{13}$ and $n_{e}^{3} r_{33}$ and calculated $n_{c}^{3} r_{c}$ figures of merit of lithium niobate crystals singly doped with Ho ${ }^{3+}$, Tm ${ }^{3+}$ and $\mathrm{Yb}^{3+}$ as function of the concentration of dopant.

indices induced by a change of composition and by doping will require a correction in the $\mathrm{EO}$ coefficients of the order of $5 \%$, below the accuracy of the measurements.

The values for each individual EO coefficient of each crystal are deduced of an average of a minimum of ten experimental measurements and after suppression of the extreme obtained values. Within this procedure and the equipment used for experimental measurements, the accuracy in the EO coefficient values is $\pm 5 \%$. The dependence of the EO figure of merit, $F$ on the molar dopant concentration is shown for singly doped with $\mathrm{Ho}^{3+}$, $\mathrm{Tm}^{3+}$ and $\mathrm{Yb}^{3+}$ series in Figure 1 and for doubly doped with $\mathrm{Er}^{3+}-\mathrm{Yb}^{3+}$ series in Figure 2. The various experimental values of $F$ with the calculated $\mathrm{EO}$ coefficients are summarized in Table 1.

We can see in Figures 1 and 2 that for all rare-earth singly and doubly doped LN samples in the considered concentration range, the unclamped EO coefficients of the third column of the EO are slightly smaller than the values in the undoped or pure congruent crystal and do not change with dopant concentration within the experimental error.
It is to be noted that in LN crystals, this quasi-constant value of unclamped EO coefficients $r_{13}$ and $r_{33}$ versus rareearth dopant concentration has to be emphasized, since this coefficient presents a very large and non-monotonous dependence for crystals doped with other ions, such as Zn, $\mathrm{Mg}$ and $\mathrm{Zr}[11,49,74]$.

Based on the general model of the role of the dopant for the EO coefficients of inorganic crystals and thus for LN, it is now well established that the ionic contribution is the predominant contribution considering the change in the composition, i.e. the $\mathrm{Li} / \mathrm{Nb}$ ratio of in the doping effect $[22,23,50-53,56,57]$. In this model, the two main contributions being considered are the deformability of the oxygen $\mathrm{NbO}_{6}$ and $\mathrm{LiO}_{6}$ octahedron, at low dopant concentration and the change in the ionic and electronic polarizabilities of the $\mathrm{Nb}$ ions for higher concentrations. Indeed, due to the incorporation of extrinsic defects in the congruent LN structure, with dopant having various atomic sizes and polarizabilities and, also, as function of their concentration, the dopants are incorporated in either $\mathrm{Li}$ or $\mathrm{Nb}$ or both sites with the necessary decreasing of the number of $\mathrm{Nb}_{\mathrm{Li}}$ 

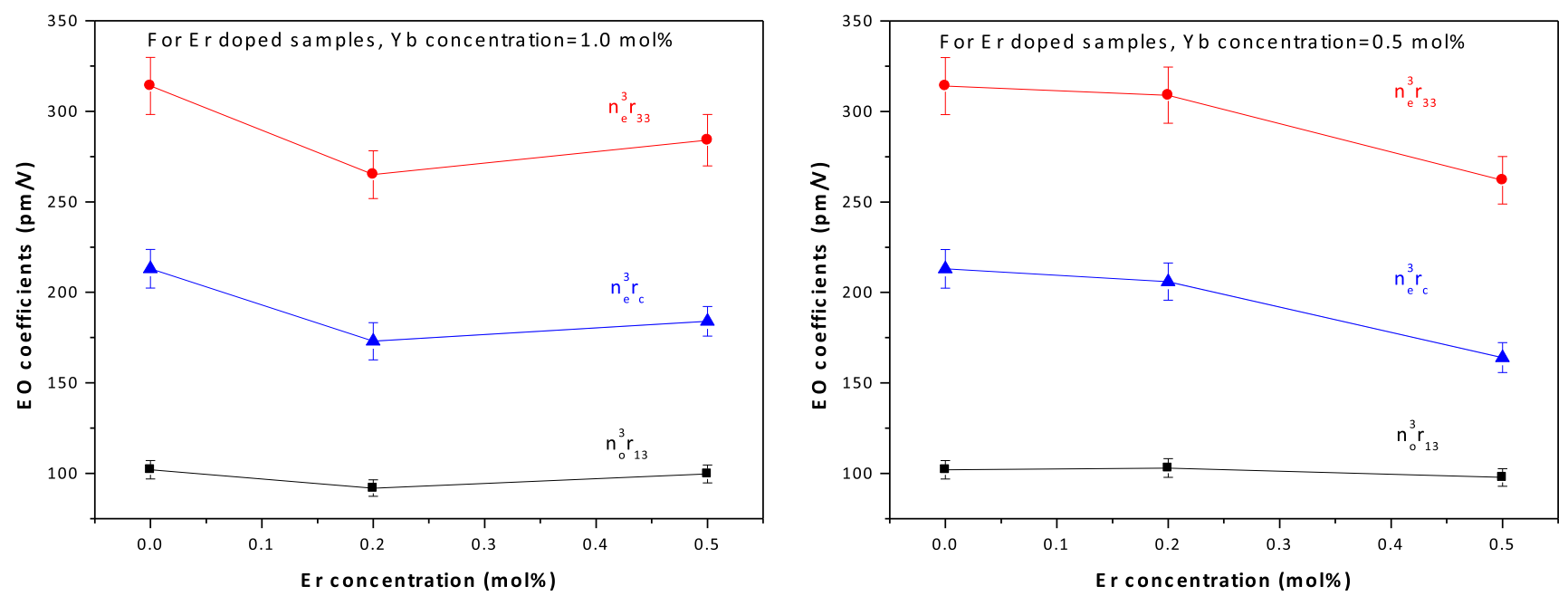

Fig. 2. The experimental $n_{o}^{3} r_{13}$ and $n_{e}^{3} r_{33}$ and calculated $n_{c}^{3} r_{c}$ figures of merit of lithium niobate crystals co-doped with Er ${ }^{3+}-\mathrm{Yb}^{3+}$ as function of the concentration of dopant.

antisites and creation of ionic vacancies [35]. In other worlds, the incorporation of dopants will induce nonstoichiometric and extrinsic defects in the structure with in fine, an ordering of the structure when dopants are incorporated in antisite and disordering when dopants are incorporated on both sides or when the compensation phenomena create ionic vacancies. By this, we can see that, in the low dopant concentration range, i.e. when the polarizability of $\mathrm{Nb}$ ions is slightly influent, the lattice deformability, mainly due to the deformability of the oxygen octahedron, will have a straightforward effect in the change with dopant concentration of the EO properties. Based on this model, the large changes in the EO properties observed in pure LN [29] with the composition or in doped LN with $\mathrm{Zn}, \mathrm{Mg}$ and $\mathrm{Zr}$ dopant $[22,23,50,53]$ have been explained as well as the small changes in $\mathrm{Hf}$ or In doped LN $[41,45,57]$. Thus, in the current EO characterizations of LN doping or co-doping with rare earth elements, the dopants concentrations are in a range at relatively low level and dopant ions do not largely affect the EO coefficients as they do not significantly affect the stiffening of the LN lattice.

Now, considering the co-doping Er-Yb influence on the EO properties. Our results point out that no significant change between the $\mathrm{EO}$ properties behavior can be observed between the two $\mathrm{Yb}$ series, $[\mathrm{Yb}]=0.5 \mathrm{~mol} \%$ and $[\mathrm{Yb}]=1 \mathrm{~mol} \%$ within the experimental errors and in the Er concentration range. This result points the interest of co-doping $\mathrm{LN}$ crystals with $\mathrm{Yb}^{3+}$ ions to $\mathrm{Er}^{3+}$ ions allowing to associate in a same device, both the interesting efficient energy transfer from $\mathrm{Yb}^{3+}$ ions to $\mathrm{Er}^{3+}$ and EO properties for laser and modulation or Q-switch applications.

\section{Conclusion}

We have experimentally determined the unclamped EO coefficients in various singly and doubly doped LN crystals with rare earth elements. Three series of singly doped LN with $\mathrm{Yb}^{3+}, \mathrm{Ho}^{3+}, \mathrm{Tm}^{3+}$ and two series of doubly $\mathrm{Er}^{3+}-\mathrm{Yb}^{3+}$ elements were characterized by EO measurements performed on a Mach-Zehnder interferometer associated to the MDM. Whatever the rare-earth dopant in samples, in the considered concentration range, both $r_{13}$ and $r_{33}$ present small dependences with the dopant concentration with, however, within the experimental error, a general tendency to slightly decrease from the coefficient in the pure congruent sample. This small doping effect is of interest for electro-optical applications. Indeed, as the EO coefficients of rare-earth doped LN remain quasi-constant with dopant concentration, the present study confirms the interest of LN crystals doped with rare earth elements for multi-functional applications associating the EO modulation one. Indeed, these doped LN crystal families offer the possibility to adapt the second functional property involved in the consider application by an adjustment of the concentration with only a slight modification of the EO properties.

\section{References}

1. Y. Furukawa, M. Sato, K. Kitamura, Y. Yajima, M. Minakata, J. Appl. Phys. 72, 3250 (1992)

2. M.D. Fontana, K. Chah, M. Aillerie, R. Mouras, P. Bourson, Opt. Mater. 16, 111 (2001)

3. D.A. Bryan, R. Gerson, H.E. Tomaschke, Appl. Phys. Lett. 44, 847 (1984)

4. T.R. Volk, N.M. Rubinina, M. Woehlecke, J. Opt. Soc. Am. B 11, 1691 (1994)

5. E. Krätzig, O.F. Schirmer, Photorefractive centers in electrooptic crystals, in Photorefractive Materials and Their Applications I, edited by P. Günter, J.P. Huignard (Springer, Berlin, 1988), pp. 131-167

6. C.W. Thiel, Y. Sun, R.M. Macfarlane, B. Thomas, R.L. Cone, J. Phys. B At. Mol. Opt. Phys. 45, 124013 (2012)

7. F. Abdi, M.D. Fontana, M. Aillerie, P. Bourson, Appl. Phys. A 83, 427 (2006) 
8. G.E. Peterson, M. Glass, A. Carnevale, P.M. Bridenbaugh, J. Am. Ceram. Soc. 56, 278 (1973)

9. J.F. McCannt, J. Pezytg, P. Wilsen, J. Phys. E 15, 322 (1982)

10. D. Eimerl, S. Velsko, L. Davis, F. Wang, Prog. Cryst. Growth Charact. Mater. 20, 59 (1990)

11. F. Abdi, M. Aillerie, M. Fontana, P. Bourson, T. Volk, B. Maximov, S. Suluanov, N. Rubinina, M. Wöhlecke, Appl. Phys. B 69, 795 (1999)

12. G.P. Banfi, P.K. Datta, V. Degiorgio, D. Fortusini, Appl. Phys. Lett. 73, 136 (1998)

13. S. Zhang, Q. Wang, X. Xu, C. Dong, X. Zhang, P. Li, Opt. Laser Technol. 35, 233 (2003)

14. W. Jin, K.S. Chiang, Q. Liu, J. Light Wave Technol. 28, 1477 (2010)

15. D.L. Zhang, J. Kang, W.H. Wong, D.Y. Yu, E.Y.B. Pun, Opt. Lett. 40, 4715 (2015)

16. I. Baumann, S. Bosso, R. Brinkmann, R. Corsini, M. Dinand, A. Greiner, K. Schäfer, J. Söchtig, W. Sohler, H. Suche, R. Wessel, IEEE J. Sel. Top. Quantum Electron. 2, 355 (1996)

17. H. Suche, T. Oesselke, J. Pandavenes, R. Ricken, K. Rochhausen, W. Sohler, S. Balsamo, I. Montrosset, K.K. Wong, Electron. Lett. 34, 1228 (1998)

18. R. Wessel, R. Ricken, K. Rochhausen, H. Suche, W. Sohler, IEEE J. Quantum Electron. 36, 394 (2000)

19. C. Becker, T. Oesselke, J. Pandavenes, R. Ricken, K. Rochhausen, G. Schreiberg, W. Sohler, H. Suche, R. Wessel, S. Balsamo, I. Montrosset, D. Sciancalepore, IEEE J. Sel. Top. Quantum Electron. 6, 101 (2000)

20. K. Chah, M. Aillerie, M.D. Fontana, G. Malovichko, E. Kokanyan, Ferroelectrics 186, 13 (1996)

21. K. Chah, M. Aillerie, M.D. Fontana, G. Malovichko, K. Betzler, E. Kokanyan, Opt. Commun. 136, 231 (1997)

22. K. Chah, M.D. Fontana, M. Aillerie, P. Bourson, G. Malovichko, Appl. Phys. B 67, 65 (1998)

23. K. Chah, M. Aillerie, M.D. Fontana, G. Malovichko, Opt. Commun. 176, 261 (2000)

24. Ch. Becker, A. Greiner, T. Oesselke, A. Pape, W. Sohler, H. Suche, Opt. Lett. 23, 1194 (1998)

25. B.K. Das, R. Ricken, W. Sohler, Appl. Phys. Lett. 82, 1515 (2003)

26. B.K. Das, R. Ricken, V. Quiring, H. Suche, W. Sohler, Opt. Lett. 29, 165 (2004)

27. C. Becker, T. Oesselke, J. Pandavenes, R. Ricken, K. Rochhausen, G. Schreiber, W. Sohler, H. Suche, R. Wessel, S. Balsamo, I. Montrosset, D. Sciancalepore, IEEE J. Sel. Top. Quantum Electron. 6, 101 (2000)

28. E. Cantelar, J. Sanz-Garcia, G. Lifante, F. Cusso, P. Pernas, Appl. Phys. Lett. 86, 161119 (2005)

29. F. Abdi, M. Aillerie, P. Bourson, M.D. Fontana, K. Polgar, J. Appl. Phys. 84, 2251 (1998)

30. A.M. Petrosyan, R.K. Hovsepyan, E.P. Kokanyan, R.S. Feigelson, Proc. SPIE 4060, 106 (2000)

31. E.P. Kokanyan, L. Razzari, I. Cristiani, V. Degiorgio, J.B. Gruber, Appl. Phys. Lett. 84, 1880 (2004)

32. E.P. Kokanyan, Ferroelectrics 341, 119 (2006)

33. P. Minzioni, I. Cristiani, V. Degiorgio, E.P. Kokanyan, J. Appl. Phys. 101, 116105 (2007)

34. J.Q. Xu, W.Y. Du, Q. Sun, W.H. Wong, D.Y. Yu, E.B. Pun, D.L. Zhang, Opto-Electron. Rev. 25, 89 (2017)

35. F. Abdi, M. Aillerie, P. Bourson, M.D. Fontana, J. Appl. Phys. 106, 033519 (2009)
36. M. Aillerie, P. Bourson, M. Mostefa, F. Abdi, M.D. Fontana, J. Phys. 416, 012002 (2013)

37. T. Volk, V. Pryalkin, N. Rubinina, Opt. Lett. 15, 996 (1990)

38. M. Aillerie, P. Bourson, M. Mostefa, F. Abdi, M.D. Fontana, J. Phys. 416, 012001 (2013)

39. J.K. Yamamoto, K. Kitamura, N. Iyi, S. Kimura, Y. Furukawa, M. Sato, Appl. Phys. Lett. 61, 2156 (1992)

40. J.K. Yamamoto, T. Yamazaki, K. Yamagishi, Appl. Phys. Lett. 64, 3228 (1994)

41. M. Abarkan, A. Danielyan, S. Sewastianow, N. Theofanous, M. Aillerie, S. Kostritskii, E. Kokanyan, J. Phys. 879, 012005 (2017)

42. F. Rossella, D. Grando, P. Galinetto, V. Degiorgio, E. Kokanyan, Ferroelectrics 352, 143 (2007)

43. L. Razzari, P. Minzioni, I. Cristiani, V. Degiorgio, E.P. Kokanyan, Appl. Phys. Lett. 86, 131914 (2005)

44. S. Li, S. Liu, Y. Kong, D. Deng, G. Gao, Y. Li, H. Gao, L. Zhang, Z. Hang, S. Chen, J. Xu, J. Phys. Condens. Matter 18, 3527 (2006)

45. P. Minzioni, I. Cristiani, J. Yu, J. Parravicini, E.P. Kokanyan, V. Degiorgio, Opt. Express 15, 14171 (2007)

46. Y. Kong, S. Liu, Y. Zhao, H. Liu, S. Chen, J. Xu, Appl. Phys. Lett. 91, 081908 (2007)

47. N. Argiolas, M. Bazzan, M.V. Ciampolillo, P. Pozzobon, C. Sada, L. Saoner, A.M. Zaltron, L. Bacci, P. Minzioni, G. Nava, J. Parravicini, W. Yan, I. Cristiani, V. Degiorgio, J. Appl. Phys. 108, 093508 (2010)

48. H. Liu, Q. Liang, M. Zhu, W. Li, S. Liu, L. Zhang, S. Chen, Y. Kong, J. Xu, Opt. Express 19, 1734 (2011)

49. M. Abarkan, M. Aillerie, N. Kokanyan, C. Teyssandier, E.P. Kokanyan, Opt. Mater. Express 4, 179 (2014)

50. M. Aillerie, M. Abarkan, S. Kostritskii, E.P. Kokanyan, Opt. Mater. 36, 1238 (2014)

51. M. Abarkan, A. Danielyan, N. Kokanyan, M. Aillerie, A. Movsesyan, S. Kostritskii, E.P. Kokanyan, J. Phys. 879, 012004 (2017)

52. S.M. Kostritskii, M. Aillerie, J. Appl. Phys. 111, 103504 (2012)

53. M. Abarkan, M. Aillerie, J.P. Salvestrini, M.D. Fontana, E.P. Kokanyan, Appl. Phys. B 92, 603 (2008)

54. T.R. Volk, N.M. Rubinina, Ferroelec. Lett. Sect. 14, 37 (1992)

55. Y. Kong, J. Wen, H. Wang, Appl. Phys. Lett. 67, 280 (1995)

56. W.Y. Du, Z.B. Zhang, S. Ren, W.H. Wong, D.Y. Yu, E.Y.B. Pun, D.L. Zhang, Opt. Laser Technol. 88, 152 (2017)

57. W.Y. Du, P. Zhang, Z.B. Zhang, S. Ren, W.H. Wong, D.Y. Yu, D.L. Zhang, J. Phys. Chem. Solids 100, 101 (2017)

58. Q.R. Zhang, X.Q. Feng, Phys. Rev. B 43, 12019 (1991)

59. I.V. Kityk, M. Makowska-Janusik, M.D. Fontana, M. Aillerie, F. Abdi, J. Phys. Chem. B 105, 12242 (2001)

60. E. Barnes, N. O'Connell, N. Balli, M. Pokhrel, A. Movsesyan, E. Kokanyan, D. Sardar, Opt. Express 22, 26222 (2014)

61. G. Demirkhanyan, E. Kokanyan, H. Demirkhanyan, D. Sardar, M. Aillerie, J. Contemp. Phys. 51, 28 (2016)

62. A. Lorenzo, H. Jaffrezic, B. Roux, G. Boulon, J. García-Solé, Appl. Phys. Lett. 67, 3735 (1995)

63. M.N. Palatnikov, I.V. Biryukova, N.V. Sidorov, A.V. Denisov, V.T. Kalinnikov, P.G.R. Smith, V.Y. Shur, J. Cryst. Growth 291, 390 (2006)

64. E. Cantelar, J.A. Muñoz, J.A. Sanz-García, F. Cusso, J. Phys. Condens. Matter 10, 8893 (1998)

65. E. Cantelar, R. Nevado, G. Lifante, F. Cussó, Opt. Quantum Electron. 32, 819 (2000) 
66. M. Stoffel, H. Rinnert, E. Kokanyan, G. Demirkhanyan, H. Demirkhanyan, M. Aillerie, Opt. Mater. 57, 79 (2016)

67. E. Cantelar, J.A. Sanz-Garcia, F. Cusso, J. Cryst. Growth 205, 196 (1999)

68. M.N. Palatnikova, I.V. Biryukova, N.V. Sidorova, A.V. Denisovb, V.T. Kalinnikova, P.G.R. Smith, V.Ya. Shur, J. Cryst. Growth 291, 390 (2006)

69. E. Montoya, A. Lorenzo, L.E. Bausa, J. Phys. Condens. Matter 11, $311(1999)$

70. M. Quintanilla, E. Cantelar, J.A. Sanz-Garcıa, F. Cusso, Opt. Mater. 30, 1098 (2008)

71. M. Aillerie, N. Théofanous, M.D. Fontana, Appl. Phys. B 70, $317(2000)$
72. M. Abarkan, J.P. Salvestrini, M. Aillerie, M.D. Fontana, Appl. Opt. 42, 2346 (2003)

73. M. Abarkan, J.P. Salvestrini, M.D. Fontana, M. Aillerie, Appl. Phys. B 76, 765 (2003)

74. Y. Furukawa, M. Sato, F. Nitanda, K. Ito, J. Cryst. Growth 99, 832 (1990)

Open Access This article is distributed under the terms of the Creative Commons Attribution License https://creativecom mons.org/licenses/by/4.0 which permits unrestricted use, distribution, and reproduction in any medium, provided the original author(s) and source are credited.

Cite this article as: Nune Mkhitaryan, Jean Zaraket, Ninel Kokanyan, Edvard Kokanyan, Michel Aillerie, Electro-optic properties of singly and doubly doped lithium niobate crystal by rare earth elements for optoelectronic and laser applications, Eur. Phys. J. Appl. Phys. 85, 30502 (2019) 